[Reprinted from "Transactions of the Liverpool Biological Sogiety," Vol. XXVII, 1913.]

$$
\text { D. D. }
$$

The Early Days of

Comparative Anatomy

BY

F. J. COLE, D.Sc.,

Professor of Zoology, University College, Reading.

LIVERPOOL :

C. Tinling \& Co., Ltd., Printers, 58, Victoria Street. 

Digitized by the Internet Archive in 2016 


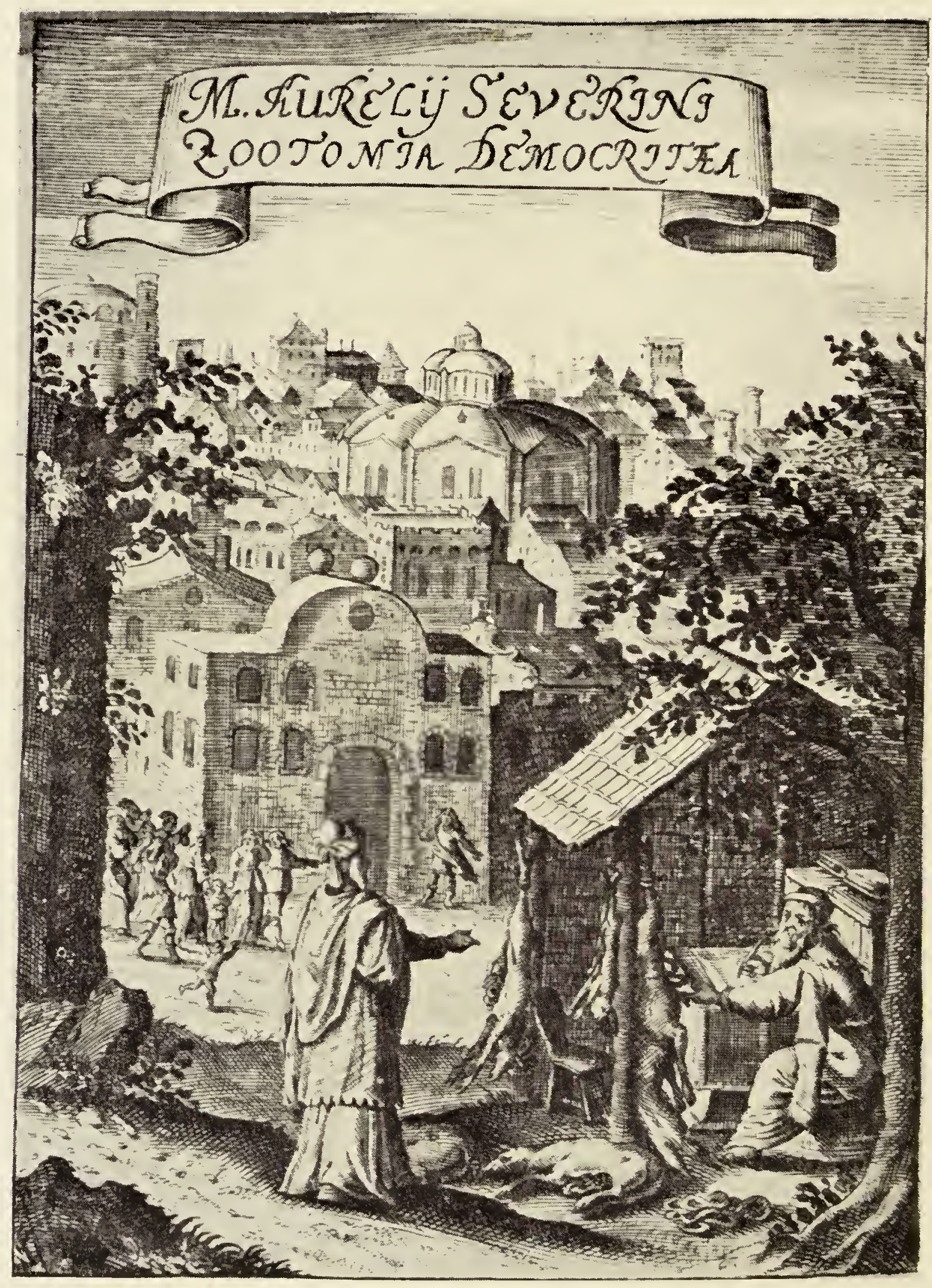




\section{THE EARLY DAYS OF COMPARATIVE ANATOMY.}

By F. J. COLE, D.Sc.,

Professor of Zoology, University College, Reading.

(Communicated February 14th, 1913.)

I feel I owe to the members of the Society some explanation, I had almost said apology, for selecting as the subject of this address, a topic the biologist so generally avoids as history. I must therefore endeavour to justify a venture which may appear to some both hazardous and unprofitable.

It is the necessity, but also the misfortune, of the man of science to focus his efforts on the field that lies in front, and to cast no "longing lingering look behind." Unlike other branches of study it would be invidious to mention, the biologist, so far as research is concerned, suffers from an embarrassment of riches. The untrodden paths are so numerous and inviting, and the temptation to add his small contribution to the sum of human knowledge is in itself so laudable, that he eagerly assumes the yoke of the pioneer, and rejects the wisdom which comes after the event. He doubts not the mission of his own generation, or the adequacy of the knowledge and methods he finds at his hand. What he fails to realise is that there is nothing new under the sun. That the same mental limitations which frustrated the observer of the XVII. century may defeat the investigator of to-day. The lack of balance, that just revenge of neglected knowledge, may destroy, in the loose 
thinking of an unguarded moment, the faithful observation of months.

Now the study of history, whilst it cannot exclude error, completes and rounds off the learning of the modern schools, and assists in keeping the worker within his limits. It carries him into a quaint and unaccustomed atmosphere. It flogs his imagination. He can foregather with men, surely as great as any now, and with this added advantage. He can see them as they really are, his judgment preserves its sense of proportion, and the genius of the old masters is neither magnified nor obscured by the closeness of the observer. When Robert Boyle approaches him and says-I have demonstrated the Spring of the Air, he replies-excellent, admitted, but why did you advise me to cure my complaints by frying a live toad on a shovel and hanging its ashes round my neck. In this common paternity of a great discovery and a fragment of romantic mediaevalism, we detect the rattle of the skeleton in the cerebral cupboard. The human mind is good only in parts, and the man of genius is discovered as mortal. Thus history teaches us to be cautious in honouring the drafts of authority, and to accept a statement, not because it is made by Galen, and endorsed by the Society of the Curious in Natural History, but because it is sound.

But there is another, and to me a greater, reason why the history of Biology should be cultivated. It introduces the element of literary interest, perhaps not the least important of the differences which separate the unimaginative from the creative artist. Philemon Holland's translation of Pliny's History of the World, published in 1601, is an education in the formidable combination of literature and science. The honours 
student who can be persuaded to mitigate the strong and occasionally contentious waters of modern biology with some such diluent will not deny the dissipation. We run a serious risk, as teachers, in neglecting the humane side of scientific literature, and the academic world has already incurred the contemptuous reproach of Edward Gibbon, who tells us that after he left the University his interest in books began to revive. He himself practised the wisdom of extending his mental horizon in every direction, and he attended a course of lectures on anatomy by Dr. William Hunter, the eloquent brother of the more famous John, with the result that we may "sometimes track him in our own snow."

II.

To insist that there can be no comparative anatomy without evolution, is to be bound by all the limitations of a strict and academic mind. For the elucidation of an organ in one animal by a comparison with the corresponding feature in another was practised in the earliest days of anatomy. The explanation of this community of structure is another story, although naturally a closely related one. The development of an idea may be slow and uncertain, and we must not expect, in groping underground for the roots of knowledge, to find the products which characterise a later growth in the freedom of the atmosphere. To rigorously distinguish, in the early days of anatomy, between a Znotomist, who merely dissected an animal, and a Comparative Anatomist, who resolved the evolution of its parts, is to apply a modern standard to an ancient work, and to deny that comparative anatomy has arisen by any process of natural growth with which we are acquainted. Who can doubt that in the following two cases, both of them long 
antecedent to the period of evolution-and one could quote many others-we have the origin and practice of a method which was to exercise the genius of a Cuvier and a Johannes Müller.

1. Belon in 1555 compares the skeleton of a man in some detail with that of a bird. Apart from a natural failure to identify the clavicle of the bird, and the consequent misinterpretation of the coracoid, together with some hesitation for which the elongated metacarpus is responsible, his comparison is correct at every point. The confusion of the radius and ulna in the figure is an engraver's error, since the text on this point is quite sound. In the leg of the bird, where we should have expected him to go badly astray, in the absence of any knowledge of its development, he only commits the venial error of mis-stating the extent of the tarsus, whilst he adroitly avoids the pitfall of comparing the tarsal joint with the knee, and of regarding the tarsometatarsus as a new element. The bones of the bird, he tells us, approach those of other animals more closely than a casual inspection at first suggests.

2. Nehemiah Grew in 1681 compares the chambered stomach of the sheep with the stomach of man. He says: "The fourth venter is called Abomasus: by butchers, the Read. The only analogous one to that in a man."

That the early anatomists themselves understood and valued the method is abundantly clear. Again I might quote numerous instances, but four must suffice.

1. Malpighi in 1666 contrasts the state of anatomy in his own time with the knowledge of the ancients, and attributes the superior genius of contemporary anatomy to the investigation of the Invertebrate and lower Vertebrate animals, as opposed to the practice of the 
ancients, who confined their work rather to the higher forms of life.

2. Samuel Collins in 1685 says: "And I humbly conceive the great use of comparative anatomy is to illustrate the structure, actions, and uses of man's body, which are sometimes more clear in that of other animals, than in ours; as I have discovered in frequent dissections to my great satisfaction, pleasure and admiration."

3. Alexander Pitfeild in 1687 observes that as regards "the Construction, Fabrick, and Genuine Use of the Parts of Animals, and even of Man: A Knowledge no way better to be obtained than from the Comparative Anatomy of divers Animals; that Texture of Parts being discoverable in one Animal, which Nature has conceal'd and made more obscure in another."

4. Edward Tyson, in his scholarly work on the anatomy of the Chimpanzee, published in 1699, remarks: - To render this Disquisition more useful, I have made a comparative Survey of this Animal, with a Monkey, an Ape, and a Man. By viewing the same Parts of all these together, we may the better observe Nature's Gradation in the Formation of Animal bodies, and the Transitions made from one to another; than which, nothing can more conduce to the Attainment of the true Knowledge, both of the Fabrick, and Uses of the Parts."

Here we may enquire when the expression Comparative Anatomy first appears in the literature of Biology. In 1675 Grew published a tract entitled "The Comparative Anatomy of Trunks" [of trees]. This was reprinted during his own lifetime, and under his supervision, in 1682, when the word comparative, for some unexplained reason, was erased. In the meantime, in 1681, he had also issued "The Comparative Anatomy of Stomachs and Guts begun," in which he again commits 
himself to the same expression. In 1675 Nicholas Hoboken uses the expression "anatomia comparata " in his work on the anatomy of the seal, and earlier still, in 1672 , it is employed by Thomas Willis in his treatise on the Soul of Brutes. It is curiously difficult to be certain on a point such as this; but I imagine that Walter Charleton, in the first edition of the Onomasticon Zoicon, published in 1668, was the first to distinguish "Anatomia comparativa" as a branch of Biology.

\section{III.}

This is neither the time nor the occasion to explore the work of the ancients. Aristotle has been sufficiently expounded, and we can only hope that Galen will soon achieve an English commentator and an English dress. That his work is partly, if not largely, comparative does not require for its demonstration the methods of the higher criticism. When he says that the lower jaw is in two halves, that there is a separate premaxilla, that there are eight segments in the sternum, that the transverse processes of the lumbar vertebra are directed forwards, that the sacrum and coccyx have three pieces each, and that the femur is curved, he is not describing the anatomy of man. His apologists in the sixteenth century exhausted all the resources of desperation in his defence as a human anatomist, and it was seriously claimed by Sylvius that the structure of the human body had changed since the time of Galen. The explanation of this assumed change was itself eagerly debated, and it is difficult to acquit the Galenists of levity in ascribing the straight femur of man to the substitution for the airy freedom of the toga of the cylindrical garments of a later age.

But it must not be concluded that the outstanding 
figures of Aristotle and Galen exhaust the list of the ancient anatomists. Anaxagoras dissected the head of a Ram, Empedocles examined the structure of many animals and discovered the cochlea of the ear, whilst Alcmaeon practised the undesirable combination of erotic poetry and anatomical study. Among the lesser lights of anatomy, however, Democritus occupies a unique position. We know, on the somewhat doubtful authority of the elder Pliny, that he dissected the Chameleon, and "verely made so great reckoning of this beast that hee compiled one entire booke expressely of it and hath anatomized everie severall member thereof." There is also a strong tradition, but a lack of convincing evidence, of a meeting between Democritus and Hippocrates. The legend does not gain in credibility by the fact that modifications of it introduce the persons of other actors such as Aristotle and Heraclitus. It is interesting as an "abuse of the privilege of fiction," but also because it is the subject of the engraved title of almost the earliest comprehensive treatise on comparative anatomy we have-the Zootomia Democritaea of Severini. The laughing philosopher, having retreated from the world to pursue his studies among the amenities of the neighbouring cemetery, becomes the object of the contempt or pity of the citizens of his native Abdera. They draft a letter, of which the extant copy is a mediaeval forgery attributed to Epictetus, invoking the assistance of the Father of Medicine. The engraving represents in the background the lively distress of the simple Abderitians, whilst in the foreground we observe Democritus, seated in what appears to be a butcher's shop, awaiting the composed and stately figure of the physician. He is asked why he occupies himself in the dissection of the viler creatures, and he replies in 
philosophic idiom that his object is to discover the cause of folly, the seat of which he suspects is in the bile. The conference speedily establishes the wisdom and sanity of the patient, and Hippocrates retires to allay the anxiety of the citizens. Or in the expressive language of Severini-_"Says Hippocrates, 'By Jove, O Democritus, thou speakest truly and wisely.'

Between the decline of classical learning and the invention of printing at the middle of the fifteenth century, we search with little success for any example of comparative anatomy, and this period is represented almost exclusively by one small work-the Anatomia Porci of Copho. Details of the life of Copho are entirely wanting - we do not even know which of the two men of that name is responsible for the Anatomia, but judging from contemporary references it must have been written before the end of the thirteenth century. This little tract, which extends to only a few pages of type, may be traced through eleven printed versions ranging from 1502 to 1852 . It is a work of little merit or distinction, and there are no illustrations. Its interest lies not so much in what is disclosed, as on the light it throws on the state of biological science at the time it was written. And in comparing it with the mass of accurate and detailed anatomy collected centuries before in the works of Galen, we lament the total eclipse of the republic of letters during the era known as the dark ages.

Copho addressed himself to the internal anatomy of the pig, as he tells us, because of its resemblance to that of man, and he claims that the same reason explains the comparative researches of the ancients. His point of view is clearly that of the physician, and we gain the impression that he has taken to anatomy as a doubtful and irksome necessity. He describes in a brief and 
elementary manner the anatomy of the mouth and of the chest and abdomen. He mentions the larger vessels, and demonstrates the alveolar nature of the lungs by inflating them with a quill.

\section{IV.}

That ill-defined and shifting upheaval which resulted in the revival of learning produced little effect on the biological sciences, which lagged far behind as if dependent on the invention of printing. In comparative anatomy the revival of research may be dated from the memoirs published in 1573 and 1575 by Volcher Coiter, the "excellent friend" of Eustachius, and a product of the school of Padua, one of the first and certainly the greatest of all schools of anatomy. The grip of the middle ages no longer paralyses the energies of the observer, and the works of Coiter challenge the understanding and accuse the ignorance of his generation. Apart from the inevitable description of the development of the chick, a subject which has excited the curiosity of naturalists from the time of Aristotle, Coiter compares the skeleton of man with that of a higher and lower ape, and again with that of a fox. He is disposed to fasten rather on points of difference than to emphasize homologies. He deals with the skeleton and soft parts of all classes of Vertebrates except Fishes, and his section on the anatomy of Birds is especially admirable. He describes in remarkable detail, and illustrates with well-drawn figures, the complex tongue and hyoid of the woodpecker, the internal organs of Birds, their skeleton and muscles, and he explains how the pectoral muscles are used in flight. He adds to his achievements a scheme in which the classification of Birds is attempted almost for the first time. 
A contemporary of Coiter's, but one who considerably outlived him, was Jerome Fabrici, a name grateful to Englishmen as that of the teacher of William Harvey, and who, by demonstrating the valves of the veins to his English pupil, played no inconsiderable part in the discovery of the circulation. He is almost the last of the great Paduan anatomists. The decline of the school, already apparent in his own time, made fatal progress in the next two generations, and Spigelius was the last of the old anatomists of Padua whose reputation extended beyond the common room of his own University. But Fabricius was the most famous teacher of anatomy of his day, and students assembled from the whole of Europe to profit by his lectures and demonstrations. The University paid him the sincere and grateful compliment of building what was regarded as an "ample and splendid" theatre to accommodate his large classesa gloomy and unsuitable erection which has happily survived the censure of posterity. Time has failed to endorse his abilities as worthy of the great traditions of his chair, and it is difficult to forgive, though it is easy to understand, the lack of enterprise which handed over to a pupil a discovery properly his own. And as a comparative anatomist Fabricius shines with no steadier light. The conspicuous example of self confidence and independent judgment provided by his most illustrious predecessor in the chair of anatomy at Padua does not inspire him to trust in his own genius and fortune, and to bring a severe and critical faculty to bear upon the writings of the ancients. His respect for classical authority, in accordance with the most conservative traditions of the human mind, is constantly at variance with the evidence of his own senses. He moves forward, he hesitates, he looks back; he is 
overwhelmed by the misery of doubt and distraction. Yet it must not be concluded that he failed to achieve results both interesting and important. He compares the skeleton of the limb of the horse and man, and corrects the old and natural blunder of the position of the knee and elbow. He writes on the comparative anatomy of the hyoid bone and of the gut, and I ought specially to mention his striking work on the comparative anatomy of the eye, ear and larynx, published at Venice in the year 1600, in which he compares in detail the skeleton and muscles in a number of animals, mostly mammals. He was a skilled, and almost a great, technician, and if we are to distinguish in these early days between a zootomist and a comparative anatomist, Fabricius must be assigned an honourable position among the first explorers of the former school.

\section{V.}

But the sixteenth century reserved for its close the brightest achievement of an awakening science. As if anatomy were in the air there appeared at Paris in 1594 a small and imperfect treatise by Jean Héroard on the osteology of the horse, and almost immediately afterwards Carlo Ruini, a senator of Bologna, issued his volume on the anatomy and diseases of the same animal. It is to be regarded as the logical outcome of the Vesalian tradition, and it resembles, but does not equal, the masterpiece of the founder of anatomy in almost every detail. Like the Fabrica of Vesalius, it set a standard which posterity could only approach by working up painfully to it from below.

It is instructive to the genius of a speculative age to trace the parallel between these two works. In both cases we observe an inflexible determination to exhaust 
the anafomy of one type, and to avoid vain and argumentative digressions by the way. And it is significant that whenever the author turns aside from this high determination, he becomes involved in disaster. Thus Vesalius in a parenthesis on the skull of the crocodile tells us that the lower jaw is fixed and that the upper jaw moves-a statement which recalls an equally misguided belief on the part of Oliver Goldsmith. Ruini, in his turn, becomes entangled in a greater snare when he describes a backward flow of blood along the veins. Ruini's work, as we should expect from the cumbrous nature of his subject, is more topographical than Vesalius', but as far as possible he goes through the animal system by system in the same patient and exhaustive manner. We know the anxiety of Vesalius to secure the best illustrations available at the time, how he employed a pupil of Titian's to make the drawings and engrave them on wood, and how he indulged a whimsical, and not always amiable, fancy of throwing his figures into attitudes and providing them with a rustic setting. In all this Ruini is his close, and not always successful, imitator, although the last figure of the muscles of the horse in Book V. is a work with distinct artistic feeling. You have only to compare it with any of the pirated copies engraved on copper to realise, in spite of its coarseness, the superior merit of the original figure. Both anatomists suffered from scandalous and shameless plagiarism. Their successors, lacking the ability to excel or to extend, frankly adopted the infamous alternative of theft. There are several pirated French versions of Ruini, including the Perfect Cavalier, and Saunier's Complete Knowledge of the Horse. In England, Snape's Anatomy of an Horse, first published in 1683, is little more than a plagiarised 
translation of Ruini brought up to date, and the figures, with a few exceptions, are close copies of most of his plates, without any mention of his name. In one instance Snape acknowledges that the figure is "taken out of a French authour," which seems to indicate that he was himself, like the receiver of stolen goods, ignorant and careless of the real owner of the property. In another plate the only original feature of importance is the addition of a dragon-fly to the background, and finally a caricature of Ruini's not.very successful figure of the entire skeleton is stated to have been "drawn exactly by one that I keep standing in a Press." Snape's introduction can only be regarded as a reckless exhibition of mendacity, which calls for the condemnation of posterity. He boldly assumes the laurels of a pioneer, and claims that none have gone before or showed him the way. In submitting the merit of the figures he says: "I have therefore accordingly by a curious draught or delineation represented to you such observations as are made in true dissections," and again, in discussing the relative merits of books and dissections, he discovers an unconscious vein of candour when he urges the student "not to trust too much to these copies, as I may call them, without practicing upon the original body itself." The whole transaction, and the early literature of Biology affords many such, recalls the indignant rhetoric of Dr. Knox: "As to the hack compilers, their course is simple: they will first deny the doctrine to be true; when this becomes clearly untenable they will deny that it is new; and they will finish by engrossing the whole in their next compilations, omitting carefully the name of the author."

Ruini's treatise, which passed through fourteen editions from 1598 to 1769 , but which is nevertheless 
little known, is divided into five books, each with its own series of wood engravings. The original edition is now very scarce. The first book deals with the anatomy of the head generally, and includes the skull, the muscles and vessels, the teeth at different ages, the brain and its membranes, the sense organs, and the mouth and tongue; book II. is concerned with the neck and thorax, its skeleton and muscles, the hyoid and larynx, the nerves and vessels of the neck, the heart and lungs and the diaphragm; book III. relates to the abdominal contents and tail, the gut and its glands, mesentery and peritoneum, renal organs, the great vessels of the abdomen, the vertebral column and skeleton of the pelvic region, and we note also a scheme of the portal vein clearly inspired by that of Vesalius; book IV. is an account of the genital organs in both sexes, the development of the horse, and the structure of the foetus and placenta; book V. completes the work with a detailed description of the topographical anatomy of the fore and hind limbs, to which he has evidently given close attention, and in addition there are seven figures of a general character summarising the more important features of the skeleton, veins and arteries, nerves and muscles. The schemes of the arteries, veins and nerves recall the least inspired and convincing efforts of Vesalius.

\section{VI.}

The transition from the monographic to the systematic treatment of animal anatomy is a step so familiar to the modern anatomist that the slow and halting movements of the old masters arouse only his wonder and contempt. The possibilities and importance of monographic anatomy had been successively demon- 
strated, one might almost add exhausted, by Galen, Vesalius and Ruini. The limitations of work of this character were apparent to Coiter, and he endeavoured according to the measure of his ability to introduce the new element of philosophic enquiry and discussion. But it is difficult to make the dry bones live, and even when the first step has been taken towards the possibility of a second, and the second itself is in fact impending, the tyranny of tradition may for a time inhibit a departure which is none the less inevitable. So it was with comparative anatomy. The first step had been brilliantly accomplished, but the expected advance was still delayed.

In the meantime some tentative efforts were being put forth. Early in the seventeenth century Casseriusfirst the domestic servant, then the pupil, and finally the successor of Fabricius at Padua-had published his works on the organs of sense and voice. He definitely repudiates the practice, which, owing to the influence of Fabricius, was no longer rigidly observed, that human anatomy should constitute the only charge on the time of the Professor, and his two works owe their value to the fact that they are largely comparative. He was however less a philosopher than a practical anatomist, and his text, which is marred by various errors, does not attain the level of his plates. But he does achieve the distinction of endeavouring to explain the fabric of man by appeals to the lower animals, and that the fundamental principles of comparative anatomy were feebly stirring in his mind, an examination of his writings establishes beyond question.

The clear and penetrating intellect of William Harvey, the immediate successor in time of Casserius, enabled him to leap the gap. His own procedure is well known-he urges the necessity of comparative studies. 
He holds that an Insect is worth investigating in itself, but still more for what it suggests of the greater truths of biological science. In the strict academic sense we recognise in Harvey the first comparative anatomist. He seizes every opportunity of illustrating his views, and stimulating his imagination, by reference to the viler creatures, as he calls them, and the beating of the heart of an Amphipod is not only interesting as such, but to him it throws a powerful light on the beating of the heart in man. He says: "Had anatomists only been as conversant with the dissection of the lower animals as they are with that of the human body, the matters that have hitherto kept them in a perplexity of doubt would, in my opinion, have met them freed from every kind of difficulty."* Nothing could be plainer. Here we have the whole practice and rationale of comparative anatomy divulged in the year 1628 .

Unfortunately the greater part of Harvey's researches on comparative anatomy, and they must have been considerable, were lost or destroyed in the unhappy tumults of the Civil War. He used to tell John Aubrey that of all the losses he had sustained no grief was so crucifying to him as the loss of these manuscripts, and, as it is, his published work contains new observations on sponges and zoophytes; bees, wasps, hornets and flies; mussels, snails, and slugs; crabs, shrimps, and crayfish; fishes, toads, frogs, serpents, tortoises and birds. Even his study in generation, based as it is largely on the chick, includes numerous acute and original references to other animals, and is thus the first essay in comparative embryology.

* Willis's translation. "Veruntamen, si in dissectione animalium aeque versati essent, ac in humani cadaveris anatome exercitati: Res haec in dubio, quae omnes perplexos retinet, palam absque omni difficultate mea sententia elucesceret." De Motu Cordis, first ed., 1628, p. 33. 
But of all the undertakings stimulated by the varied activities of the seventeenth century none discovers our interest more than the Zootomia Democritaea of Severini, published in 1645. As a surgeon he favoured the stern and ruthless school of iron and fire-a school of the blackest mediaeval cast, surrounded by all the terrors of torture and mutilation. We search in vain in his animal anatomy for the strength and boldness which his reputation as a surgeon would lead us to expect. He is crude, diffuse and superficial, his descriptions are often mere catalogues of the coarser anatomical facts, and many of his figures are so original as to be unlike the objects they represent. His work might have been written in the preceding century, before the possibilities of anatomy had been revealed by Vesalius. Not that he is unfamiliar with the works of his predecessors, all of whom are quoted with the surprising and important exception of Ruini. It is at once gratifying to our national pride, and illustrative of the expansive powers of true genius, that Severini should have been an almost exact contemporary of William Harvey.

Human and comparative anatomy are distinguished by Severini as Andranatomy and Zootomy. In a long general section, which embraces also the anatomy of plants, he recognises the unity of the Vertebrate animals, including man, and regards divergences from the type as due to disturbances of function. The general similarity he attributes to Divine design. In comparing the anatomy of the ape and man he considers their affinity so patent that the ape should be exploited for medical purposes, and therefore stress is laid only on the points of difference. $\mathrm{He}$ is not misled by the specialised character of birds, but here he appears to have been ignorant of the work of Belon. Man is regarded, 
conformably to the humour of his time, as the "archetype" of all animals. The superficial resemblance of the Viper and the Eel entraps him into arranging their distinguishing features in parallel columns, but he is evidently in doubt himself, and the reader is left to draw whatever conclusions he can from this irregular alliance. He pursues in some detail the anatomy of most orders of mammals; of birds, fishes and cephalopods; and there are in addition observations on tortoises, lizards and snakes; frogs and toads; insects and arachnids; crayfish, slugs and snails; and earthworms. A section on anatomical methods concludes the treatise. As examples of the matter and scope of his work, he understood the structure and physiology of the complex stomach of Ruminants, and he describes the welldeveloped sclerotic of separate bony plates in the birds of prey.

\section{VII.}

The constitution of the French Academy of Science in 1666 established a school of morphology to which the modern development of comparative anatomy may be directly traced. The Academy divided its forces into Mathematicians, who met on Wednesdays, and Physicists, as Biologists were then called, who met on Saturdays. As we gather from contemporary engravings, and from the reports of their proceedings, the Academy in no sense corresponded to the scientific society of to-day, but was rather a laboratory for the practical examination and discussion of natural phenomena. We note with satisfaction, but with little surprise, that in the subsequent decline of the Academy up to its reconstitution in 1699, the biological section alone retained its vitality, and the earnest and virile band of comparative anatomists were 
never disposed to calculate the odds of a game of chance, or to exercise their genius on the details of ornamental gardens. The longevity of a public man is variously ascribed, according to the prejudice of the critic, to the reward of virtue or to a supernatural evasion of the justice of Heaven, and the remarkable longevity of the early Parisian anatomists, only one of whom died before the age of 75 years, may well provoke the doubts of the irreverent mind. Their leader was Claude Perrault, a member of a versatile family, who abandoned the profession of arms for the pleasures of art, and became one of the leading architects of his age. But he is no less distinguished as an anatomist and a physician, and it is mainly to his influence that a number of the early members of the French Academy, who are usually referred to in contemporary literature as the "Parisians," initiated a movement which has since been actively and continuously developed. The principal members of the "company" were the "acute and lucky Pecquet," as Robert Boyle used to call him, Louis Gayant, the great figure of Duverney, Moyse Charas, and the Jesuit Father Thomas Gouye. It is a commonplace both in literature and science that a great book seldom fails to attract an adequate illustrator, and the Parisians were fortunate in enlisting the services of Sébastien Le Clerc, again a well-known architect, and an engraver on copper of outstanding merit. Only some of the plates are signed by Le Clerc, but there are no peculiarities of execution sufficient to justify the belief that other engravers were employed. Of the numerous subsequent editions none approach the first in the excellence of the illustrations, and it is therefore all the more unfortunate that so few copies were printed, since the work is now practically unobtainable. We learn from Alexander 
Pitfeild that it had become very scarce even in the seventeenth century, and in recent times only one copy has come into the market for many years.

At the risk of obscuring the main issue in a cloud of detail, I am tempted to give a brief history of the publications of the Parisians, the bibliography of which beguiled the leisure of several weeks. Their first venture was the anonymous issue of a small tract of 27 pages and two plates, published at Paris in 1667. They had dissected a "large fish" [Alopias vulpes] on June 24, 1667, and a Lion on June 28 of the same year, and the tract contains a description of their results. Two years later they published a larger work of 120 pages and five plates, dealing with the anatomy of a Chameleon, a Beaver, a Dromedary, a Bear and a Gazelle. They were now definitely committed to a more ambitious enterprise, and, encouraged by the interest which these papers had aroused, they projected an extensive work on comparative anatomy on a scale not hitherto attempted. This was published anonymously, at the expense of the King, in two sections in 1671 and 1676, but in the latter year both sections were issued together with Perrault's name on the new title page. The preparation of the work was begun by Perrault, Pecquet and Gayant, and the material they employed had died of sickness in the Royal Menagerie mostly during the winter months. Gayant died in 1673 and Pecquet in the following year, but the work not being completed, Duverney was happily invited to assist in the final stages, and his services are specially commended by Perrault. In 1680 the "Essais de Physique" were published by Perrault-a work which passed through several editions, and which includes numerous observations on comparative anatomy.

The death of Perrault, which occurred in 1688, left 
Duverney in charge of the conduct of the work, but for some reason which is still obscure he failed to apply himself vigorously to the discharge of his trust. He discovered among Perrault's papers descriptions of sixteen new animals, but he refrained from publishing them, and his attempt to bring out a new edition of the series only resulted in the publication of the first section in the year 1700. Urged by the Academy to greater efforts, he undertook the preparation of a revised and extended edition in 3 vols. quarto, but he died in 1730 before this could be accomplished. The duty was then entrusted by the Academy to Winslow, Petit, and Morand, who examined the papers bequeathed to the Academy by Duverney, compared them with previous editions, and completed their task by December, 1731 . They included the sixteen unpublished descriptions of Perrault, and added a chapter on the Viper by Charas, which had appeared separately in 1669. A fourth volume based on material left by Duverney, Méry, and Lahire was not completed, and Duverney's work on the anatomy of Fishes is still unpublished.

In 1686 and 1689 Father Tachard published descriptions of the two missions dispatched by the Jesuit Fathers to Siam. The fathers interpreted their mission in a liberal and catholic spirit, and they supplemented their sacred duties by observations on the natural history of the country. Many animals were dissected on the spot, and others were forwarded to Paris, where they aroused the lively interest of the members of the Academy of Science. In this way the Academy received in 1687 a Crocodile, Tarentola [Platydactylus], a Camel and a Tiger, and the anatomy of these animals by Father Gouye is included in the edition of the memoirs we are now considering, which was at length published in 
1732-1734. This, therefore, is the most complete edition of the monographs of the Parisians, and it is happily not difficult to obtain, although it cannot compare in interest or execution with the first complete edition of 1676 .

The booksellers of the seventeenth and eighteenth centuries provoke the resentment and tax the labour of the bibliographer by their loose methods of publication. In the first instance the sheets were printed and issued under the name of the responsible agent, but he retained the right of farming them out to all who chose to apply for them, the purchaser being permitted to print a new title, and to publish the work from his own town, and under his own name and date. This procedure was naturally exploited for the profit of the unscrupulous, and the case of Dr. William Cowper, who purchased 300 copies of the sheets of Bidloo's atlas, and sold them under his own name as author, is familiar to students of the history of anatomy. Thus it comes about that the same work may be published a number of times, from many centres, and under a variety of dates. Copies even of the same issue may bear varying dates, an altered date, or no date at all. The conscientious bibliographer, who sees his leisure slipping away from him, but who dare not assume the identity of editions he has not personally examined, can only arraign the practice and submit to his fate. And it does occasionally happen that he is rewarded by some small detail he must otherwise have missed. The monographs of the Parisians are a tedious example of this pernicious custom, and I doubt whether, even now, I have unravelled all the ramifications of this sprawling publication. After the issue of the completed first edition in 16r6, another edition was published at Paris in 1682. The first English edition appeared in 
1687, the text translated by Alexander Pitfeild and the plates re-engraved by Richard Waller, whose engraved title was plagiarised in Valentini's Amphitheatrum Zootomicum in 1720. Unhappily the English plates are little better than caricatures of the finished engravings of Sébastien Le Clere, but we must not forget that they represent the maiden efforts of the engraver. An imperfect French edition, together with Father Gouye's independent observations, appeared in 1688. Then follow numerous issues, some of them incomplete, in English, French, Dutch and German down to 1758, when the work ceased to be printed after a life of almost a century. As an illustration of the fatigues and surprises of this bibliographic chase, I have in my own library an English edition dated 1701, of which no other copy can be traced-a circumstance which combines features of satisfaction and despair.

In the just applause of their own discretion the Parisians happily disclose their methods of work. The dissections were carried out, not by any individual, but in session of the whole company, and nothing was committed to paper which failed to command the ready assent of all present. They say: "That which is most considerable in our Memoires is that unblemishable evidence of a certain and acknowledged Verity. For they are not the work of one private person, who may suffer himself to be prevail'd upon by his own opinion" ... "This so precise exactness in relating all the particulars which we observe, is qualified with a like care to draw well the figures, as well of the entire animals, as of their external parts, and of all those which are inwardly concealed. These parts having been considered, and examined with eyes assisted with Microscopes, when need required, were instantly designed 
by one of those upon whom the Company had imposed the charge of making the descriptions; and they were not graved, till all those which were present at the dissections found that they were wholly conformable to what they had seen. It was thought that it was a thing very advantagious for the perfection of these figures to be done by a hand which was guided by other sciences than those of painting, which are not alone sufficient, because that in this the importance is not so much to represent well what is seen, as to see well what should be represented." Characters presenting no feature of special interest are hardly more than catalogued, but they explore with patience and curiosity any departure from the commonplaces of anatomy, such as the compound stomach of the Gazelle, and the claws of the Lion. Their limitations are well defined, and not always consistent. They expect too close an agreement with the human type, a belief which constrains the imagination without preventing error, for they deny, after only a casual inspection, that the chamaeleon has an ear. Their lack of familiarity with the microscopical method introduces other difficulties, and they hesitate to distinguish between the kidney of the chamaeleon and its testis. Repeated efforts are made to link up structure and function. Thus they endeavour to associate the production of voice with a vertical glottis, and its absence with a transverse one-an essay in philosophic anatomy after the manner of Aristotle.

It would be improper to take leave of the work of the Parisians without some statement of the range of their investigations, and of the results they achieved. And in doing so I shall confine myself to the first complete edition, the extended later issues belonging to another period and generation. The animals were dissected and 
described in the order in which they fell into their hands, and no attempt is made to classify them. The Parisians are careful to identify their examples, and adequate space is devoted to this; but they are above everything committed to anatomical research. Over 30 species are described, and the groups represented are those commonly drawn upon in stocking a menagerie. The species include 1 Elasmobranch, 1 Chamaeleon, 1 Chelonian, 8 Birds, 1 Insectivore, 2 Rodents, 8 Carnivores, $\tau$ Ungulates, and 2 Monkeys.

In the Lion they detected the independent blood supply of the cortex and medulla of the kidney, and an examination of the human kidney from the same point of view revealed a similar phenomenon, contrary to the statements of Vesalius. This they establish by injecting the veins with milk. The anatomy of the Chamaeleon is treated at length. They note the structure of the curious eyelid, and draw attention to the old error of attributing co-ordinated movements of the eyes to the optic chiasma, or the "joining of the optic nerves," as it was then called, for they found a chiasma in the Chamaeleon-an animal with remarkable powers of independent movement of the eyes. The stiffness of the neck is held responsible for this free and antagonistic behaviour of the eyes. They describe the unusual character and extent of the lungs, and inflated them through the trachea. The anatomy of the tongue claims a large share of their attention, and they observed how it was used in feeding. Their discussion of the mechanism of the tongue, however, is highly ingenious, but unsound. It is nevertheless interesting to note that the protrusion or erection of an organ, such as the tentacle of the Snail, in response to vascular pressure rather than to muscular contraction, was familiar to these seventeenth century anatomists. But 
the tongue of the Chamaeleon is not an example of this effect.

The lobulated kidney of the Bear, composed of 56 sub-divisions, each having its artery, vein, and efferent duct, is compared with the 10-lobular kidney of the Otter, and contrasted with the superficially lobulated kidney of the Porpoise and the newly-born human infant, which are stated to be essentially parenchymatous. The figures of Alopias vulpes are poor, but the description is accurate. The boundaries of the different regions of the gut are correctly defined, the distal limb of the stomach and the extent of the duodenum and rectum being determined on morphological criteria. The Parisians usually refer to the work of their predecessors, but they appear to have been unaware that the spiral valve had been already described by Severini. They give a good account of the heart and its valves, and note the backward extension of the nerve of the lateral line. The anatomy of the castoreum of the Beaver is accurately and minutely explained. It is distinguished from the scent glands of the Civet Cat, which are regarded as secondary sexual characters. They establish that the castoreum is not a reproductive gland, as formerly believed. Their only failure of importance is to miss the smallest subdivision of the second pair of glands, but on the other hand they note the difference in structure between the two sets of glands, and find also a difference in the character of the secretion. They point out, both in the Beaver and in the Civet Cat, that the contents of the glands have been produced by the action of the gland tissue on the blood-one of the earliest declarations of a physiological doctrine of supreme importance.

In the Seal they are again attracted by the lobulated nature of the kidney, which, with its superficial plexus 
of ressels, is satisfactorily dealt with, but the investigation of the heart involves them in unexpected confusion. They are of course aware that the Seal is not a fish, and camnot breathe under water. They are also aware that in the Mammalian foetus blood is diverted from the right side of the heart to the left through the foramen ovale in order to avoid the lungs, and they draw from this the fatal conclusion that the foetus does not respire. They profess to have found, and, indeed, may actually have found, a perisisting foramen ovale in the heart of the Seal, and they believe that when the animal dives, and remains some time below water, the circulation follows the same course as in the intra-uterine embryo. The fact that the Seal is only below water for a relatively short time, whilst the circulation in the foetus remains the same throughout foetal life, should have warned them of the risk of assuming an interruption in the normal circulation every time the breathing organs were cut off from the atmosphere.

The Parisians describe for the first time in the Barbary Cow the valves in the primary hepatic branches of the portal vein, which are correctly interpreted as preventing the reflux of blood into the parent vein. These valves are not present in man. But a still more remarkable vascular phenomenon is discussed in the Stag, where the external and internal jugular veins are stated to possess sixteen valves disposed in six rows, the cavities of the valves being directed, not towards the heart, but towards the head. They fully recognise the unusual and incredible nature of this arrangement, which is explained as preventing "the too great impetuositie of the bloud which falls in its returne from the brain into the axillary branches." I am not aware that this statement has ever been confirmed or denied, and 
it is of course possible that the Parisians were mistaken in their facts.

The ancients were induced by the apparent affinity of the Hedgehog and Porcupine to unite them under the one genus of Echinus, but the Parisians, after anatomising examples of both animals, conclude that they are "very different," both as regards external characters and internal organs. But they go further than that, for they recognise the true affinity of the Porcupine with such forms as the Hare and the Beaver, and the large Rodent caecum of the Porcupine is contrasted with the reduction of that organ in the Hedgehog. By ligaturing the thoracic extremity of the azygos vein, and inflating it backwards, they establish a posterior anastomosis with the iliac vein, as in man-a point of detail we hardly expect at this early period. The large glandular vesiculae seminales of the Hedgehog, however, naturally overtax their knowledge and experience, and they interpret them as vascular organs for the elaboration of the blood before it reaches the testes.

The chapter on the Monkey only calls for comment as regards the description of the laryngeal region. Its close resemblance to the speaking larynx of the human species is converted into an agreement so exact as to emphasize dramatically the splendid isolation of man, and to concentrate the philosophic genius of the company on the happy but speechless monkey. They say: "For the ape is found provided by Nature of all these marvellous organs of speech with so much exactness, that the very three small muscles which do take their rise from the apophysis styloides, are not wanting, altho this apophysis be extreamly small. This particularitie do's likewise shew that there is no reason to think that agents do performe such and such actions, because they are found with organs 
proper thereunto: For according to these philosophers, apes should speake, seeing that they have the instruments necessary for speech." An opening such as this could hardly fail to provoke the ingenuous advocates of Godmade man, and consequently we find Tyson, in confirming the statements of the Parisians, drawing an inference which he says the "Atheists can never answer." Yet neither the Parisians nor 'Tyson could be expected to comprehend those structural refinements which alone can evoke the harmony of speech, and it was reserved for the more instructed vision of Camper to supply a profane but convincing explanation of the silence of the forest.

The structure of Birds early engaged the more serious attention of the old anatomists, and it is therefore in accordance with tradition that the most complete and accurate section of the work of the Parisians is that devoted to Birds. They detect the connection between the calibre and length of the gut and the character of the food, and they note also that the absence and relative development of the caeca are determined by the same factor. They describe the sinus rhomboidalis of the spinal cord, first in the Eagle, and afterwards extend the discovery to other birds. Its contents are found to be a "white and glutinous humour," the removal of which by a duct is considered to be possible. The pecten of the eye is investigated and described in several birds, and its pigmented and vascular nature is clearly perceived. The pecten is supposed to be wanting only in Apteryx, but the Parisians were unable to find it in the Numidian Crane. They undoubtedly anticipate the modern view that the function of the pecten is the "nourishment of the humours of the eye." In the Cormorant they note the absence of the caeca formerly believed to be present in all Birds, and their description of the curious stomach 
is excellent. Although it differs markedly from the type usually present in Birds, they nevertheless distinguish a glandular portion, corresponding to the proventriculus, and a muscular portion, corresponding to the gizzard. Its unusual form they attribute to the piscivorous diet of the species.

But the bird most grateful to the curiosity of the Parisians, and of which they dissected eight examples, is the Ostrich, and they give a lengthy and excellent description of its anatomy. They pursue in detail the structure of the feathers, and contrast them with the quill feathers of a flying bird. In this they appear to have been ignorant of the work of Robert Hooke on the morphology of feathers, first published in the Micrographia of 1665. They understood the structure and function of the barbs and barbules, and they recognise the double advantage of a concavo-convex feather-its greater rigidity and grip of the air on the downward beat, and its diminished resistance on the upward stroke. They devote ample space to an account of the air sacs, which is on the whole complete and accurate, and they understood the connection between the air sacs and the lungs, and how they became filled with air. They regard the partitions separating the air sacs as a series of diaphragms, and we note with regret a tendency to go back on their acceptance of the doctrine of the circulation in the description given of the passage of the blood through the lungs. In the section on the brain an incident is mentioned which illustrates how the abuse of advertisement betrayed the confidence of mankind in a trusting and superstitious age. To demonstrate the powerful virtues of a healing balsam, its inventor would plunge a knife into the head of a bird, whose life he then professed to restore by the application of his celestial ointment; and 
provided the knife had been thrust into the fissure between the cerebrum and the cerebellum, the position of which the operator had prudently explored by private dissection, a miracle was duly proclaimed by an amazed and unsuspecting public.

In the Cassowary they describe and figure the long aftershaft of the feathers, and note the peculiar nature of the stomach and its valve, although the dilated duodenum is misinterpreted as a second chamber of the gizzard. They compare, not without reason, the air sacs of the bird with the branching lung of the Chamaeleon, but the chapter fixes our attention on account of the discovery of the nictitating membrane of the eye. This they had seen before, and it is mentioned casually here and there, but it was in the Cassowary that they were stimulated to disclose the complete facts. It is a remarkable piece of research, illustrated by simple workmanlike figures, and more detailed and trustworthy than many modern versions. They describe, in addition to the six normal muscles of the eye, the two muscles which draw the membrane over the cornea, and they show that the object of the movement is to keep the surface of the eye clean. The mechanics of the origin and doubling of the pyramidalis are understood and explained, and they realise that the quadratus does something more than withhold the tendon of the pyramidalis from the optic nerve. These are facts we have all at some time laboriously verified for ourselves, and we can therefore extend our sympathetic admiration to the men by whose genius and labour they were first laid bare; but the true merit of such a performance is rather the obligation it imposes on posterity of precise and exhaustive observation.

The chapter on the Indian Tortoise is an instructive display of the strength and weakness of the Parisians; 


\section{4}

TRANSACTIONS LIVERPOOL BIOLOGICAL SOCIETY.

nor do they appear to have seriously respected the wishes of the King to return the specimen sufficiently intact for exhibition in the Museum. The origin and course of the cystic and hepatic ducts are worked out, the epididymes are unravelled, and their factors disclosed by the injection of a coloured fluid. The bladder is astutely recognised as comparable to the allantois of higher animals, and the urogenital organs receive masterly treatment. Even the comparative anatomy of the lung is only partially baffling, as we gather from their happy comparison of the chambered lung of the Tortoise with the almost parenchymatous lung of the Mammal. Vivisection itself is resorted to in matters of difficulty, and they were among the first to investigate the physiology of the lungs in a living animal in which respiration was maintained with a pair of bellows. The same experiment had been successfully demonstrated to the Royal Society by Robert Hooke four years before, but they go further than Hooke, and find that in the inflated lung an injection thrown into the pulmonary artery passes more readily through the capillaries into the pulmonary vein than in the deflated organ. To close the list of their successes, they discuss the nictitating membrane of the eye and its muscles, the relations of the tympanic cavity and the columella, and they realise that the extrusion of the head and the neck of the Tortoise is just as much a question of muscular contraction as its withdrawal-a simple deduction, but one which later biologists have not always comprehended. On the other hand, in spite of several ingenious-but misleading-experiments, they fail to grasp the broader facts of the Reptilian circulation. They confuse the hepatic veins with the postcaval, the aortic arches are regarded as branches of a single vessel, and, worst of all, they deny that the lungs exercise any 
effect on the blood, but are intended partly to compress the contents of the abdomen, and to act as hydrostatic organs like the swim bladder of fish. The circulation is compared with that of the Mammalian foetus, the blood passing from one side of the heart to the other, only a sufficient quantity being conveyed to the lungs to ensure the nourishment of those structures.

\section{VIII}

The influence of the Parisian School undoubtedly stereotyped for many years the character of anatomical research, and the completion of their work may well mark the close of the early struggles of comparative anatomy. Like the Insect emerging abruptly from the secret stresses of metamorphosis, our science, apparently by a single convulsion, moults the clogging accumulations of centuries, and assumes the activities of a free and independent existence. It would be unjust to claim, however, that the honours of the morphological renaissance belong solely to the founders of the French Academy of Science. They were themselves only an extreme and lively manifestation of the general revival of scientific learning, which was beginning to agitate the intellectual centres of Europe. We cannot forget that they had as contemporaries such men as Steno, Malpighi, Swammerdam, Willis and Thomas Bartholini, and whilst it must be admitted that they dominated the labours of their successors, of whom Muralt, Collins and Tyson may be quoted as examples, their contemporaries honourably staked out for themselves their own claim on the suffrage of posterity. It is with regret that we take leave of these sincere and venerable guides, and we may do so in the 
words of the greatest of all of them: "I avow myself the partizan of truth alone" . . . . . that others, "starting from hence, and the way pointed out to themadvancing under the guidance of a happier genius, may make occasion to proceed more fortunately and to enquire more accurately." 
